\title{
National Pharmacists On-the-Job Training program at the Ministry of Health in Saudi Arabia
}

\author{
Yousef Ahmed Alomi ${ }^{1}$,* (D), Saeed Jamaan Alghamdi², Radi Abdullah Alatty ${ }^{2}$ \\ ${ }^{\prime}$ The Former General Manager of General Administration of Pharmaceutical Care, The Former Head, National Clinical \\ pharmacy and pharmacy practice, The Former Head, Pharmacy R and D Administration, Ministry of Health, Riyadh, \\ SAUDI ARABIA. \\ ${ }^{2}$ General Administration of Pharmaceutical Care, Ministry of Health, Riyadh, SAUDI ARABIA.
}

\begin{tabular}{|c|c|}
\hline $\begin{array}{l}\text { Abstract } \\
\text { Objective: To explore the pharmacists on the job training at the Ministry of Health hospitals in the } \\
\text { Kingdom of Saudi Arabia. Methods: It is a descriptive analysis of pharmacists on the job training at } \\
\text { the Ministry of Health hospitals. It was within the pharmacy strategic plan 2012-2020. The study used } \\
\text { the changed pharmacy business model system and Project Management Procedure. Results: The } \\
\text { pharmacists on job training system reputable with a defined vision, mission and goals. The system had } \\
\text { some properties including human or economic and other defined in the review. The continuation of the } \\
\text { system guaranteed by risk management model explanation. Also, the monitoring and controlling of the } \\
\text { system as exemplified. The convention to operation project though closing project stage established in } \\
\text { the examination. Conclusion: The pharmacists on job training system well-known within the healthcare } \\
\text { system and pharmacy regulations. The pharmacists on the job training system are regularly refining } \\
\text { consequently at all Ministry of Health hospitals in the Kingdom of Saudi Arabia. } \\
\text { Key words: Job, Training, Pharmacists, Ministry of Health, Saudi Arabia. }\end{array}$ & $\begin{array}{l}\text { Received: 13-12-2018; } \\
\text { Accepted: 25-2-2019 } \\
\text { *Correspondence to: } \\
\text { Dr. Yousef Ahmed Alomi } \\
\text { The Former General Manager of Genera } \\
\text { Administration of Pharmaceutical Care, } \\
\text { The Former Head, National Clinical } \\
\text { pharmacy and pharmacy practice, } \\
\text { The Former Head, Pharmacy R\&D } \\
\text { Administration, Ministry of Health, } \\
\text { Riyadh, SAUDI ARABIA. } \\
\text { Phone no: +966 504417712 } \\
\text { Email: yalomigmail.com } \\
\text { Dol: 10.5530/ijpcs.2019.8.16 } \\
\text { Access this } \\
\text { article online }\end{array}$ \\
\hline
\end{tabular}

\section{INTRODUCTION}

The pharmacist training and education are crucial during the college of pharmacy and after graduating. Pharmacists are on the front lines of confirming individuals obtain proper drug and therapeutic treatments for health problems. ${ }^{[1,2]}$ The pharmacist should register at state board agency at the country level. After registration, they should get unremitting medical education to renew their license through the board. In Saudi Arabia, all healthcare providers including the pharmacist should get the license for practice. Then renewal license should be done every 3 to 5 five years. The renewal requirement is to get enduring medical education $\mathrm{h} .{ }^{[3]}$ Besides, the hospital pharmacy at accredited institutions provides a training program for the pharmacist. For instance, the residency program have been implemented in Saudi Arabia. ${ }^{[4]}$ There are several training programs available for pharmacists including orientation programs. The training program consisted of orientations of pharmacist training and education at hospitals and some clinical practice skills specific for pharmacists. Several reviews have discussed the pharmacist training program for several counties. ${ }^{[3]}$ Recent study showed the pharmacist on job training at Ministry of Health hospital was $27.6 \%{ }^{[3]}$ However, to the best of our familiarity, there are no studies or trainings conducted in Saudi Arabia which establish the pharmacists training program. The aim of this review was to explore the national pharmacists on the job training program at the $\mathrm{MOH}$ in the Kingdom of 
Saudi Arabia (KSA).

\section{Method of Development the Project}

This is a descriptive analysis of national Pharmacist on the job training program. The program was designed for $\mathrm{MOH}$ hospitals in Saudi Arabia. The task force committee consisted of expert people from the pharmacies of the $\mathrm{MOH}$ hospitals to set up a national pharmacist on-job training for hospital's pharmacies, primary healthcare centers' pharmacies and dental centers' pharmacies. The draft was sent to several reviewers of the regional pharmacy administration. The draft was corrected and updated accordingly. This took around 4 months to complete the task. The general administration of pharmacy at the $\mathrm{MOH}$ sent the final document to all the hospitals for implementation. The committee utilized and drove the pharmacist on the job training of the general administration of pharmaceutical care and some development non-MOH hospitals. The program designed and developed for all the pharmacists' jobs at the ministry of health-related hospitals. The training program was established by the authors and revised by an external expert reviewer. The program consisted of 12-month periods divided into several pharmacy practice section. The program included ambulatory care pharmacy, acute pharmacy care, drug information, intravenous admixture, pharmacy inventory management and narcotics and control unit and other services included clinical pharmacy services and pharmacy inventory management. The project underwent several phases of development including the initial phase, planning phase, execution phase and monitoring and controlling phase. In addition, it was established by using the international business model, pharmacy guidelines and project management institution guidelines for a new project. ${ }^{[5-8]}$

\section{Initiative Phase}

\section{Assessment Needs}

Most of the non- $\mathrm{MOH}$ governmental organizations had a pharmacist training program for a new graduate. The program includes 6 to 12 months pharmacist training. However, few $\mathrm{MOH}$ hospitals had a specific training program for the new graduate pharmacist. Most of the new pharmacy professionals was not completed the full training program last year. Moreover, it is tough to find an education and training program for pharmacists. This project was recognized to meet the factors that are in claim and update the information and pharmacist skills in the KSA.

\section{Market Analysis}

Most governmental and non-MOH governmental and even certification institutions have different education and training program for pharmacists. The program is designed to prepare new pharmacists' job. The program is exclusive and was established for the first time at the $\mathrm{MOH}$ institution and there is no comparable program at other institutions and private hospital pharmacies in the KSA.

\section{SWOT Analysis}

In this project, we performed a SWOT analysis. Opportunity and thread analysis method was used for this project. The strengths were integrated on-the-job training for all pharmacists at the $\mathrm{MOH}$ institutions and prepare supplementary training programs for pharmacists in the forthcoming. The weak points of this project were more job for preceptor's pharmacist and resemblances of the program for near graduate students. The opportunities were the execution of national and international standards and invite skilled pharmacist from outside $\mathrm{MOH}$ institution. The threat points were privatization of execution at $\mathrm{MOH}$ institutions.

\section{Planning Phase}

\section{The Scope of the Project}

This is a training program for new graduate pharmacist with different pharmacy practice skills at different pharmacy services. The program consists of training for a period of 12 months period at several sections of the pharmacy including acute care, ambulatory care, critical care, pharmacy narcotics and controlled medications, intravenous admixture services, Total Parental Nutrition (TPN) with chemotherapeutic preparation and introduction to the clinical pharmacy services.

\section{Vision, Missions, Goals}

The vision of this project is to have the best trained and educated expert skilled new graduate pharmacists. The mission of this project is to provide knowledge and skills through training and education program for new graduate pharmacists. The goals of this project are to provide the pharmacist with vital pharmacy practice, to improvement the pharmacist primary skills demand in practice, to prepare the pharmacist for license practice 
exam from Saudi Commission of Health Specialties, to keep up-to-date knowledge on the clinical pharmacy knowledge and skills for pharmacist and to familiarize the new pharmacist hospital market setting and residency programs.

\section{Project Description}

This is a pharmacist training program, consisting of two components: theoretical and clinical. Pharmacist should follow the rules mentioned below.

\section{Programme Objectives}

\section{Theoretical Component}

Upon successful achievement of this program, the pharmacist's roles and responsibilities shall include the following:

1. To understand the pharmacist role in the ambulatory setting;

2. To understand the departmental distribution and compounding systems;

3. To understand the pharmacist role in the inpatient pharmacy setting;

4. To understand how to prepare extemporaneous preparations;

5. To understand the pharmacist role in the preparation of sterile products;

6. To understand the concepts of laboratory safety;

7. To understand the fundamental importance of intravenous (IV) medication order processing and the role of the pharmacist;

8. To understand the role of the pharmacist in the handling and managing the pharmacy inventory section; 9. To understand the role of the pharmacist in handling and managing controlled substances and inventory and supplies;

10. To understand the role of the pharmacist in handling and managing controlled and pharmaceutical substances inventory and supplies;

11. To understand the profession of pharmacy concerning pharmacy practice and it is clinical and social context;

12. To understand the roles of other healthcare professionals and their relationship with the profession of pharmacy;

13. To demonstrate a basic knowledge of the theoretical principles and practical aspects of the formulation of solid dosage forms and the stability of medicines and apply this to patient care.

\section{Clinical Component}

After successful achievement of the clinical part of this course, the pharmacist's roles and responsibilities shall include the following:

1. To demonstrate familiarity with the activities associated with the ambulatory care setting;

2. To demonstrate familiarity with activities associated with the inpatient pharmacy;

3. To demonstrate familiarity with departmental distribution and compound systems;

4. To demonstrate the ability to prepare extemporaneous preparations;

5. To demonstrate familiarity with intravenous (IV) preparation activities;

6. To demonstrate familiarity with aseptic techniques and the handling of cytotoxic materials;

7. To demonstrate familiarity with various activities associated with the intravenous room;

8. To demonstrate familiarity with the various activities associated with the pharmacy inventory management system; 9. To demonstrate familiarity with the activities associated with the narcotic room;

10. To demonstrate familiarity with activities associated with the pharmacy store;

11. To demonstrate the ability to retrieve and use information using the available technology;

12. To demonstrate communication and numeracy skill;

13. To demonstrate practical skills in pharmacy practice including dispensing and provided written reports;

14 . To demonstrate the ability to work safely and effectively in the laboratory;

15. To demonstrate the ability to perform pharmaceutical calculations;

16. To demonstrate the ability to assess prescriptions and where necessary communicate effectively with patients and other healthcare professionals.

17. To demonstrate familiarity with the clinical activities associated with a variety of clinical specialties.

18. To familiarize the on-job training pharmacist with the development, organization and operation of the Drug Information Services.

19. To demonstrate familiarity with the clinical activities associated with medication safety.

Each core or elective rotations and the number of weeks was explored in Table 1.

\section{Plan of Cost Management}

All central or peripheral members of pharmacy 
education and training committee should comprise the financial budget with meetings $h$. The travel and accommodations expenses should be comprised in the budget. The training preceptors and lectures should comprise a financial budget.

\section{Executing Phase}

\section{Management Team}

The central and peripheral education and training committee at each region and each hospital should be recognized. The stakeholder's team should consist of hospital representatives from each section of pharmacy and should be headed by pharmacy education and training coordinators. The regional committee should consist of pharmacy coordinators from each regional hospital and should be headed by the regional coordinator of education and training in the pharmacy practice. The central committee should consist of General Administration of Pharmaceutical Care (GAPC) with assessment head, manager of pharmacy development and national drug information center.

\section{Education and Training}

The management team in association with the general administration of education and training departments showed several gatherings for preceptors and pharmacy directors with pharmacy education coordinators. The education session contained of program definitions, training elements, assessment process and extent of competencies. In addition, the written exams and electronic training scores documentation system should be conducted.

\section{Implementation of the Services}

\section{Risk Management}

There are six types of risks: budget risk, scope risks, personal risks, schedule risk, technical risks and quality risks. The project might understanding risks such as budget, personnel, schedule and quality risks. The project might experience budget risk due to the inaccessibility of the budget for education and training of trainees and preceptors. The project may be showing to personnel risks such as shortage of staff with a high workload of pharmacist training program and not enough preceptors accessible to train new pharmacists. In addition, the pharmacy preceptors may not have established education or training about the project. The

\begin{tabular}{|c|c|c|c|}
\hline No. & \multicolumn{2}{|l|}{ Modules } & $\begin{array}{l}\text { Duration } \\
\text { of } \\
\text { Training }\end{array}$ \\
\hline 1 & \multicolumn{2}{|c|}{ General Orientation } & 1 Week \\
\hline 2 & \multicolumn{2}{|c|}{$\begin{array}{l}\text { Ambulatory Care Rotation(Extemporaneous } \\
\text { Preparations and Supplies, Inventory and Controlled } \\
\text { Drug Substances }\end{array}$} & 5 Weeks \\
\hline 3 & \multicolumn{2}{|c|}{$\begin{array}{l}\text { Inpatient Care Rotation I(UD Cassette Filling, Order } \\
\text { Processing) }\end{array}$} & 5 Weeks \\
\hline 4 & \multicolumn{2}{|c|}{ Inpatient Care Rotation II( Satellite Pharmacy) } & 3 Weeks \\
\hline 5 & \multicolumn{2}{|c|}{ Primary health care rotation } & 2 Weeks \\
\hline 6 & \multicolumn{2}{|c|}{ IV Admixture Rotation } & 5 Weeks \\
\hline \multirow[t]{4}{*}{7} & \multirow{4}{*}{$\begin{array}{l}\text { Administration } \\
\text { Rotation }\end{array}$} & Pharmacy administration & 2 Weeks \\
\hline & & $\begin{array}{l}\text { Pharmaceutical care } \\
\text { administration }\end{array}$ & 1 Week \\
\hline & & $\begin{array}{l}\text { General pharmaceutical care } \\
\text { administration }\end{array}$ & 1Week \\
\hline & & Quality management orientation & 1 week \\
\hline 8 & \multicolumn{2}{|c|}{ Drug Information Rotation } & 5 Weeks \\
\hline 9 & \multicolumn{2}{|c|}{ Introduction to Clinical Practice } & 5 Weeks \\
\hline 10 & \multicolumn{2}{|c|}{ Clinical Rotation (medication safety) } & 5 Weeks \\
\hline 11 & \multicolumn{2}{|c|}{ Clinical research rotation } & 5 Weeks \\
\hline 12 & \multicolumn{2}{|l|}{ Vacation } & 35 days \\
\hline 13 & \multicolumn{2}{|c|}{ Holidays and Emergency Leave } & 2 Weeks \\
\hline & \multicolumn{2}{|l|}{ Total } & 52 Weeks \\
\hline
\end{tabular}

project might experience scope risks such as training preceptors' education, training the new pharmacist as a specialized clinical pharmacist, or surge the goals of training beyond the scope of the project. The project may be exposed to plan risks with the interruption in the timing of the training program and the lengthy period of training. The project might be exposed to quality risks due to non-qualified pharmacists being available and the training in the quality pharmacy tools and follow-up missed. The project might be exposed to other technical risks such as inaccessibility of an electronic system for the documentation, reporting and scoring of pharmacist job.

\section{Monitoring and Controlling Phase}

\section{Project Quality Management}

KPIs should be established for education and training program's follow-up and to portion the influence of the program. Several KPIs should start with initial starting of the program for occasion schedule of the program, evaluation of the trainees and the preceptors, evaluation of lectures and speakers, the impact of pharmacist in prevention of medication error, adverse drug reaction, cost avoidance and patient counseling. ${ }^{[9-11]}$ By the end 
of the training period, the complete assessment of the program should be conducted.

\section{The Closing of the Project}

Pharmacist on-the-job training at $\mathrm{MOH}$ institution is an essential tool to progress patient care and evade drug distribution problems in the Kingdom of Saudi Arabia. The annual report of pharmacist on job training should be done. Education and training programs should be frequently conducted for healthcare providers on the topic of updating new education and training regulations. Further prolonged related cost avoidance impact of pharmacist on-the-job training in the future. Annual celebration with the members involved in the project should be done.

\section{ACKNOWLEDGEMENT}

None.

\section{CONFLICT OF INTEREST}

The authors declare that there are no conflicts of interest.

\section{ABBREVIATIONS}

KSA: Kingdom of Saudi Arabia; MOH: Ministry of Health; KPIs: Key Performance Indicators; PTC: Pharmacy and Therapeutic Committee; RAPC: Regional Administration of Pharmaceutical Care; GAPC: General Administration of Pharmaceutical Care; SWOT: Strengths, Weaknesses, Opportunities and Threats; NUPCO: National Unified Procurement Company for Medical Supplies, MEs: Medications Errors.

\section{ORCID ID}

Yousef Ahmed Alomi (D, https://orcid.org/0000-0003$1381-628 \mathrm{X}$

\section{REFERENCES}

1. Asiri YA. Emerging frontiers of pharmacy education in Saudi Arabia: The metamorphosis in the last fifty years. Saudi Pharm J. 2011;19(1):1-8.

2. Al-Wazaify M, Matowe L, Albsoul-Younes A, Al-Omran OA. Pharmacy education in Jordan, Saudi Arabia and Kuwait. Am J Pharm Educ. 2006;70(1):18.

3. Alomi YA, Alghamdi SJ, Alattyh RA. National Survey of Pharmacy Practice at $\mathrm{MOH}$ Hospitals in Saudi Arabia 2016-2017: Pharmacy Education and Training. J Pharm Pr Community Med. 2018;4(1):1S-8.

4. Al-Haidari KM, Al-Jazairi AS. Establishment of a national pharmacy practice residency program in Saudi Arabia. Am J Heal Pharm. 2010;67(17):1467-70.

5. McDonough R. Writing a Business Plan for a New Pharmacy Service. The Dynamics of Pharmaceutical Care: Enriching Patients' Health. 2010;23.

6. Harris IM, Baker E, Berry TM, Halloran MA, Lindauer K, Ragucci KR, et al. Developing a business-practice model for pharmacy services in ambulatory settings. Pharmacotherapy. 2008;28(2):7e-34.

7. Sachdev G. Sustainable business models: Systematic approach toward successful ambulatory care pharmacy practice. Am J Heal Pharm. 2014;71(16):1366-74.

8. PMBOK Guide. A guide to the project management body of knowledge. Sixth Edit. Project Management Institute Inc. 2017.

9. Alomi YA, Alghamdi SJ, Alattyh RA. Strategic Plan of General Administration of Pharmaceutical Care at Ministry of Health in Saudi Arabia 2012-2022. J Pharm Pharm Scien. 2015;1(13):1-8.

10. Alomi YA, Alghamdi SJ, Alattyh RA, Elshenawy RA. The Evaluation of Pharmacy Strategic Plan in Past 2013-2016 and Forecasting of New Vision 2030 at Ministry of Health in Saudi Arabia. J Pharm Pract Community Med. 2018;4(2):93-101.

11. Alomi Y. National Pharmacy Administration Programs. BAOJ Pharm Sci. 2015;1(2):1-2. 